\title{
Consideraciones anestésicas en pacientes con COVID-19 sometidos a traqueostomía: reporte de caso
}

\author{
Anesthetic considerations in COVID-19 patients \\ undergoing tracheostomy: case report \\ Dr. Luis Leobardo Fortis-Olmedo,* Dra. Diana Stephanie Calva-Ruiz, \\ Dr. Cristian Irvin Ham-Armenta, ${ }^{\ddagger}$ Dra. Armida Pineda-Rivera, ${ }^{\S}$ \\ Dr. José Rodrigo Fernández-Sotoll
}

\begin{abstract}
RESUMEN. A finales de 2019 se identificó en Wuhan, una provincia de China, el virus causante de la enfermedad por coronavirus (COVID-19), el cual ha afectado a más de 1.5 millones de personas en todo el mundo. La fácil transmisión por aerosoles y contacto directo representa un reto para el personal que manipula la vía aérea de estos pacientes. Presentamos el caso de una mujer de 33 años con diagnóstico de neumonía por COVID-19, a quien se realizó una traqueostomía percutánea por intubación prolongada. El objetivo de esta publicación es revisar las consideraciones anestésicas durante este procedimiento en este grupo de pacientes para lograr disminuir el riesgo de contagio en el personal de salud.
\end{abstract}

ABSTRACT. At the end of 2019, the virus causing the coronavirus disease (COVID-19) was identified in Wuhan China, wich has affected more than 1.5 million people worldwide. The easy transmission by aerosols and direct contact, represents a challenge for personnel who manipulate the airway of these patients. We present the case of a 33-yearold woman diagnosed with COVID-19 pneumonia, under prolonged intubation scheduled for tracheostomy. The aim of this report is to review the anesthetic considerations during this procedure in this group of patients, in order to reduce the risk of contagion in health personnel.

\section{Abreviaturas:}

COVID-19 = enfermedad por coronavirus.

$\mathrm{EPP}=$ equipo de protección personal.

OMS = Organización Mundial de la Salud.

SARS = síndrome respiratorio agudo severo.

SARS-CoV-2 = coronavirus 2 del síndrome respiratorio agudo severo.

UTI = Unidad de Terapia Intensiva.

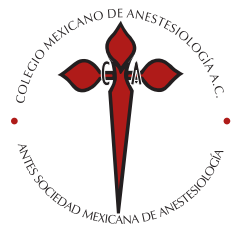

Palabras clave:

COVID-19, traqueostomía, aerosoles, equipo de protección personal.

Keywords:

COVID-19, tracheostomy, aerosols, personal protective equipment.

* Anestesiólogo del Hospital Ángeles Lomas/Centro Médico ABC.

‡ Médico Residente de Anestesiología del Hospital Ángeles Lomas.

$\S$ Anestesióloga del Centro Médico ABC.

" Médico Residente de Anestesiología del Hospital Ángeles Lomas.

Solicitud de sobretiros: Dr. Luis Leobardo Fortis-Olmedo The American British Cowdray Medical Center I.A.P. Sur 136 Núm. 116, Colonia Las Américas, Alcaldía Álvaro Obregón, 01120, Ciudad de México Teléfono: 52-30-80-00. E-mail: fortis_luis@hotmail.com

Recibido para publicación: 09-04-2020

Aceptado para publicación: 16-04-2020

\section{INTRODUCCIÓN}

A partir del surgimiento de la nueva infección por coronavirus de 2019 (2019-nCoV) en Wuhan, China, rápidamente este virus se ha extendido a más de 150 países, sumando, hasta el momento, un total de 1,353,361 pacientes infectados y 79,235 muertes de acuerdo con el último informe de la Organización Mundial de la Salud (OMS). El 12 de enero de 2020, la OMS nombró tentativamente a este virus como el nuevo coronavirus 2019 (2019-nCoV), y el 30 de enero de 2020, se anunció la epidemia de 2019-nCoV como la sexta emergencia de salud pública de relevancia internacional después del virus de influenza H1N1 (2009), la poliomielitis (2014), el ébola en África occidental (2014), el zika (2016) y el ébola en la República Democrática del Congo (2019). El 11 de febrero de 2020 se publicó un nuevo nombre para la enfermedad epidémica causada por 2019-nCoV: enfermedad por coronavirus (o más comúnmente conocido como COVID-19 por el acrónimo del inglés coronavirus disease). Ese mismo día, el grupo de estudio de coronavirus del Comité Internacional de Taxonomía de Virus nombró al virus como coronavirus 2 de síndrome 
respiratorio agudo severo (SARS-CoV-2, por sus siglas en inglés). Finalmente, el día 11 de marzo la OMS declaró al COVID-19 como una pandemia ${ }^{(1-3)}$.

\section{CASO CLÍNICO}

Se trata de una mujer de 33 años originaria del Estado de México, cuya ocupación es la de ser empleada doméstica. Al interrogatorio directo negó algún antecedente patológico o quirúrgico, sin ingesta crónica de medicamentos o viajes recientes. Acudió al Servicio de Urgencias el día 24 de marzo de 2020, en donde se valoró por el triage respiratorio. Dicha paciente refirió la presencia de un cuadro de seis horas de evolución caracterizado por fiebre, hiporexia, faringodinia y disnea. A su valoración la paciente se encontró alerta, orientada y ansiosa; se recibió con $\mathrm{SpO}_{2}$ de $80 \%$ al aire ambiente e hipotensión arterial. A la exploración física su peso reportado fue de $81 \mathrm{~kg}$, talla de $1.65 \mathrm{~m}$ (IMC de 29.7 $\mathrm{kg} / \mathrm{m}^{2}$ ), con presencia de estertores crepitantes generalizados, movimientos de amplexión y amplexación simétricos y presencia de síndrome de condensación pulmonar. En el Servicio de Urgencias se tomaron paraclínicos, los cuales reportaron únicamente bandas del 25\%; las pruebas de función renal y hepática fueron normales. Gasométricamente se encontró con $\mathrm{PO}_{2}$ de $72 \mathrm{mmHg}, \mathrm{pH}$ de $7.40, \mathrm{PaCO}_{2}$ de 31 $\mathrm{mmHg}, \mathrm{HCO}_{3}$ de $21 \mathrm{mEq} / \mathrm{L}$, lactato de $0.9 \mathrm{mmol} / \mathrm{L}$ e índice de Kirby igual a 90.

Se decidió realizar una radiografía portátil y tomografía de tórax, las cuales reportaron zonas de consolidación y opacidades en vidrio despulido (Figuras 1 y 2); bajo estas sospechas se solicitó PCR para COVID-19 y prueba rápida para influenza B, siendo ambas positivas.

Por esta razón, se inició reanimación hídrica y manejo farmacológico mediante azitromicina, hidroxicloroquina, oseltamivir y metilprednisolona. Sin embargo, la paciente continuó con cifras de hipotensión, por lo que se decidió ini-

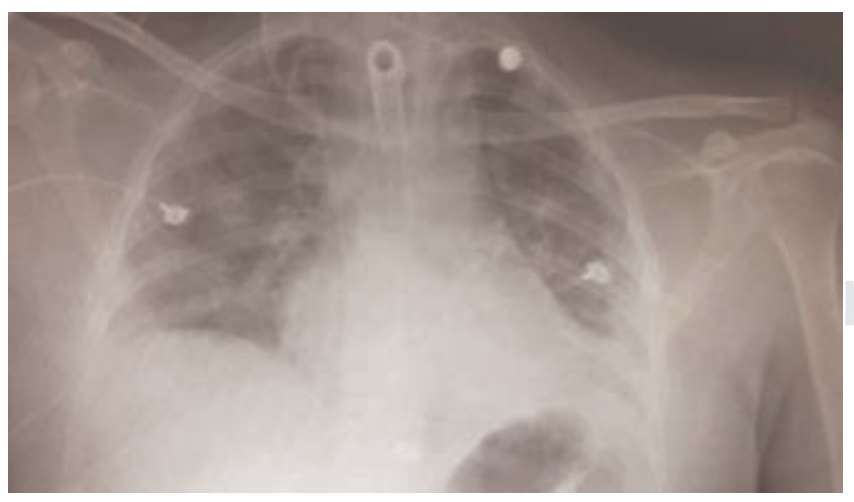

Figura 1: Radiografía portátil anteroposterior de tórax, en la cual se observan consolidaciones bilaterales e imagen en vidrio despulido.

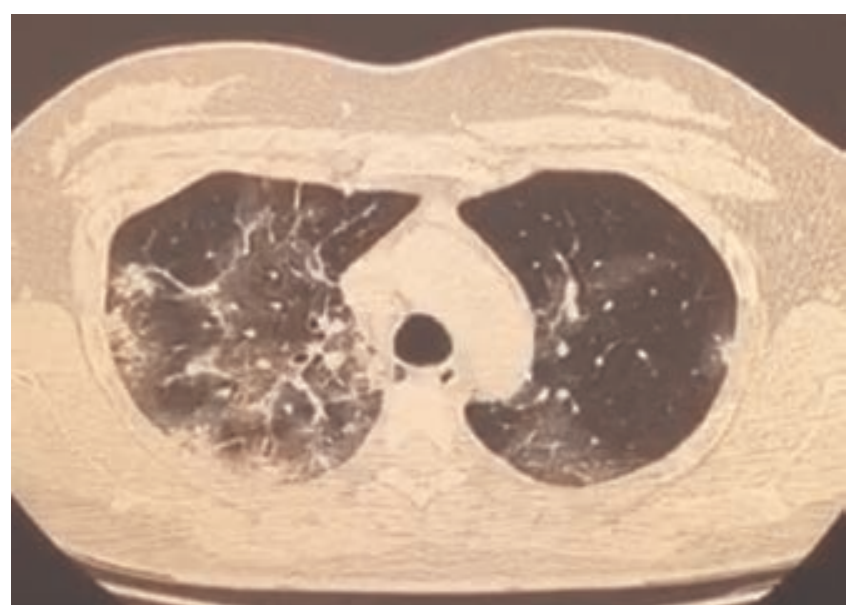

Figura 2: Tomografía axial computarizada pulmonar. En ella, se observan los infiltrados parenquimatosos bilaterales en lóbulos superiores y medios, así como también las zonas de ocupación alveolar de lado derecho.

cio de apoyo vasopresor mediante norepinefrina. Se realizó manejo avanzado de la vía aérea por presencia de taquipnea, aumento de trabajo respiratorio y persistencia de $\mathrm{SpO}_{2}$ de $86 \%$ pese al apoyo con mascarilla reservorio a $10 \mathrm{~L} / \mathrm{min}$. Se decidió su traslado a la Unidad de Terapia Intensiva (UTI) con diagnóstico de choque séptico secundario a foco pulmonar. Durante su estancia en la UTI se mantuvo en posición prono de manera intermitente, bajo sedoanalgesia y con apoyo vasopresor. Se colocó monitorización invasiva y se mantuvo bajo ventilación mecánica.

Como la paciente continuaba febril se realizó un cultivo de secreción bronquial, el cual reportó presencia de cocos Gram positivos y Candida albicans, por lo que se inició tratamiento mediante cefepima y caspofungin. Presentó mejoría hemodinámica con disminución del apoyo vasopresor, mejoría de parámetros de oxigenación por gasometría, disminución de infiltrados pulmonares en la radiografía de tórax y disminución de parámetros de ventilación, por ello se decidió la disminución de la sedación para realizarle una prueba de ventilación espontánea, la cual no fue satisfactoria por presencia de desaturación de $\mathrm{O}_{2}$ de hasta $80 \%$.

De nuevo, presentó hipotensión, entonces se reinició el apoyo vasopresor, requiriendo dosis elevadas de norepinefrina, por lo que se agregó segundo vasopresor. Por esta razón, se realizó determinación cualitativa y cuantitativa de PCR para COVID-19, el cual reportó carga viral leve. Se decidió realizar una traqueostomía percutánea por intubación prolongada hasta el día 5 de abril de 2020. También se programó procedimiento en la UTI, encontrando a la paciente bajo sedación (RASS2), con ventilación mecánica controlada por presión con una presentación $\mathrm{SpO}_{2}$ de $98 \%$ y mediante apoyo vasopresor, manteniendo TAM en $70 \mathrm{mmHg}$. 
Se colocó el equipo de protección personal (abreviado como EPP, el cual consiste en uniforme quirúrgico desechable, botas quirúrgicas, doble enguantado, bata quirúrgica desechable, goggles, cubrebocas N95, careta y doble gorro), así como la supervisión y verificación del equipo de vía aérea y de vestimenta por medio de apoyos visuales y verbales por un lector (reader). Se realizó una inducción anestésica mediante 10 $\mathrm{mg}$ de midazolam, $200 \mu \mathrm{g}$ de fentanilo y $30 \mathrm{mg}$ de rocuronio vía intravenosa, sin presentar repercusiones hemodinámicas. Durante la manipulación quirúrgica de la tráquea se realizaron pausas apnéicas alternadas con colocación de gasas sobre el sitio de incisión en la tráquea, en ausencia de manipulación quirúrgica; esto con el fin de disminuir la exposición de la vía aérea y la liberación de aerosoles.

Previo al retiro del tubo endotraqueal, se protegió la vía aérea con gasas sobre la cavidad oral y se administró una dosis subsecuente de $5 \mathrm{mg}$ de midazolam, $150 \mu \mathrm{g}$ de fentanilo y 20 mg de rocuronio. Se cambió el modo ventilatorio a modo de espera, se desinfló el globo y se retiró el tubo endotraqueal bajo visualización directa, con la inmediata colocación de cánula de traqueostomía y circuito anestésico. Posteriormente, se reinició la ventilación mecánica controlada por presión. Se logró la traqueostomía sin complicaciones y se depositó el tubo endotraqueal, así como las gasas contaminadas dentro de la bolsa de residuos biológicos. Se realizó el retiro de EPP bajo supervisión, finalizando el procedimiento anestésico y quirúrgico sin incidentes.

Posterior a la traqueostomía, la paciente presentó mejoría hemodinámica, disminuyendo considerablemente la dosis de norepinefrina, y en consecuencia, se retiró el segundo vasopresor, manteniendo presiones arteriales medias entre 54 y $87 \mathrm{mmHg}$. Clínicamente se encontró afebril y sin datos de hipoperfusión. Sin embargo, hasta el 8 de abril de 2020, la paciente no ha presentado mejoría en parámetros de oxigenación, cuyo índice de Kirby es de 148, por lo que se continúa el manejo bajo ventilación mecánica.

\section{DISCUSIÓN}

Los pacientes que son positivos para COVID-19 y que se encuentran bajo ventilación mecánica prolongada pueden requerir una traqueostomía para optimizar el destete del soporte ventilatorio. Las indicaciones para la traqueostomía en este grupo de pacientes incluyen una vía aérea de emergencia e intubación prolongada ${ }^{(4)}$. Es de gran importancia esta consideración, pues, a medida que aumentan los contagios por COVID-19, también lo hará el requerimiento de traqueostomías en pacientes con ventilación prolongada ${ }^{(5)}$.

La intubación traqueal y la traqueostomía son procedimientos generadores de aerosoles, lo que puede facilitar la transmisión de COVID-19. Por lo tanto, se recomienda que los procedimientos generadores de aerosoles en pacientes con
COVID-19, ya sea confirmado o sospechoso, se realicen sólo cuando se consideren absolutamente necesarios ${ }^{(6)}$. En general, la traqueostomía debe evitarse o retrasarse debido a los altos riesgos infecciosos del procedimiento por la mayor carga viral que puede estar presente en ese momento. Por esta razón, este procedimiento debe realizarse cuando la probabilidad de recuperación sea alta y cuando el destete de la ventilación mecánica sea el objetivo principal de la atención.

En caso de realizar una traqueostomía se debe contar con el equipo de protección personal (EPP), el cual consiste en: uniforme quirúrgico desechable, botas quirúrgicas internas y externas (estas últimas impermeables al agua y que lleguen a la rodilla), doble bata desechable, lentes de protección tipo goggles o careta para la protección de cara, cubrebocas N95, doble gorro, doble enguantado y escafandra ${ }^{(7-10)}$. Sin embargo, en Toronto, durante el brote del coronavirus de 2003, tres anestesiólogos intubaron a pacientes con insuficiencia respiratoria de causa desconocida a pesar del uso correcto del EPP, pero posteriormente contrajeron SARS, por lo que decidieron, además de las precauciones estándar, el uso de un respirador purificador de aire, el cual se debe mantener durante todo el procedimiento ${ }^{(11,12)}$.

En el caso de que se utilice EPP mejorado, como los sistemas de purificación de aire, es crucial que se sigan cuidadosamente los procedimientos de vestimenta y de retiro, ya que una extracción inadecuada puede contaminar al operador ${ }^{(5)}$.

La colocación y el retiro del EPP deben ser supervisados y dirigidos por un lector (reader). Dicho lector tiene la tarea de leer en voz alta el algoritmo de vestimenta (ayudas cognitivas) al anestesiólogo encargado del procedimiento, y con esto disminuir la omisión de pasos importantes que pudieran poner en riesgo al personal involucrado y al mismo anestesiólogo. Cabe mencionar que dichas ayudas cognitivas tienen que estar impresas y en el idioma nativo del país.

En la mayoría de los casos, durante el brote de SARS, se realizó una traqueostomía en la UTI con salas de presión negativa. Esto evitó el transporte innecesario de pacientes y la conexión y desconexión repetida de los circuitos de ventilación durante el traslado ${ }^{(5)}$.

Las traqueostomías en la UTI deben ser eventos bien organizados, meticulosamente planificados y ensayados, ya sea que se realice en el quirófano o en la UTI. Idealmente se debería estar en una sala de presión negativa en áreas bien delimitadas con rutas asignadas para el transporte de pacientes ${ }^{(5)}$.

Es muy importante que el tiempo de exposición a las secreciones en aerosol se minimice. Esto se puede lograr cuando se asegura una relajación muscular completa del paciente durante todo el procedimiento para evitar la tos; se detenga la ventilación mecánica justo antes de ingresar a tráquea; se mantenga insuflado el globo durante la ventilación, deteniendo la ventilación cada vez que se desconecta el circuito; se disminuya el uso de cauterio y se reduzca el uso de succión 
durante el procedimiento. Si se utiliza la succión se deberá realizar dentro de un sistema cerrado con un filtro viral ${ }^{(4,5,13)}$. Se debe evitar el cambio del tubo de traqueostomía hasta que la carga viral sea lo más baja posible ${ }^{(13)}$. Las traqueotomías abiertas son favorecidas sobre las traqueostomías percutáneas por la menor generación de aerosoles ${ }^{(5)}$.

Si la traqueostomía se considera difícil debido a las condiciones del paciente, se recomienda diferir el procedimiento ${ }^{(13)}$. Al término del procedimiento todo el personal tiene que ducharse antes de reincorporarse a sus actividades ${ }^{(12)}$.

Por último, recomendamos el uso de simuladores, con el objetivo de familiarizarse con el EPP, la colocación y el retiro de dicha protección. Durante una situación de estrés, como lo es al tratar a pacientes con COVID-19, es frecuente la omisión de puntos importantes. La práctica continua con casos simulados ofrece seguridad al anestesiólogo frente a casos reales.

\section{CONCLUSIÓN}

Al día de hoy, el mundo se encuentra en una crisis de salud sin precedentes debido a la pandemia generada por COVID-19. El principal objetivo se centra en controlar la infección y evitar la propagación del virus. Sin embargo, durante esta pandemia, el personal de salud, en todos sus niveles, se verá expuesto de gran manera a una alta carga viral, reportándose un alto número de personal médico infectado por este virus, principalmente el personal de primer contacto, así como el personal encargado del manejo de la vía aérea, como anestesiólogos e intensivistas.

Por esta razón, el anestesiólogo debe participar de manera activa y organizada para ayudar a contener la propagación del virus. No obstante, nunca debe descuidar la protección personal y la seguridad del personal de apoyo y del paciente.

\section{REFERENCIAS}

1. Xu Y. Unveiling the Origin and Transmission of 2019-nCoV. Trends Microbiol. 2020;28:239-240. Available from: https://doi.org/10.1016/j. tim.2020.02.001.

2. Lai C, Shih T, Ko W, Tang H, Hsueh P. International Journal of Antimicrobial Agents Severe acute respiratory syndrome coronavirus 2 (SARS-CoV-2) and coronavirus disease-2019 (COVID-19): The epidemic and the challenges. Int J Antimicrob Agents. 2020;55:105924. Available from: https://doi.org/10.1016/j. ijantimicag.2020.105924.

3. Sun P, Lu X, Xu C, Sun W, Pan B. Understanding of COVID-19 based on current evidence. J Med Virol. 2020.

4. Vukkadala N, Qian ZJ, Holsinger FC, Rosenthal E. COVID-19 and the otolaryngologist-preliminary evidence-based review. Laryngoscope. 2020.

5. Tay JK, Khoo ML-C, Loh WS. Surgical considerations for tracheostomy during the COVID-19 Pandemic: lessons learned from the severe acute respiratory syndrome outbreak. JAMA Otolaryngol Head Neck Surg. 2020.

6. Kwan A, Fok WG, Law KI, Lam SH. Tracheostomy in a patient with severe acute respiratory syndrome. Br J Anaesth. 2004;92:280-282.

7. Ceschim MRS, Candiotti KA. Airway management in highly infectious diseases: the reemergence of measles. Anesthesiol News. 2019;91-6.
8. Cheung JC-H, Ho LT, Cheng JV, Cham EYK, Lam KN. Staff safety during emergency airway management for COVID-19 in Hong Kong. Lancet Respir Med. 2020;8:e19. Available from: http://dx.doi. org/10.1016/S2213-2600(20)30084-9.

9. Wong J, Goh Q, Tan Z, Lie S, Tay Y, Ng S, et al. Preparing for a COVID-19 pandemic: a review of operating room outbreak response measures in a large tertiary hospital in Singapore. Can J Anesth. 2020. Available from: https://doi.org/10.1007/s12630-020-01620-9.

10. Wax RS, Christian MD. Practical recommendations for critical care and anesthesiology teams caring for novel coronavirus (2019-nCoV) patients. Can J Anesth. 2020. Disponible en: https://doi.org/10.1007/ s12630-020-01591-x.

11. Kamming D, Gardam M, Chung F. Anaesthesia and SARS. Br J Anaesth. 2003;90:715-718.

12. Ti LK, Lin F, Ang S, Foong TW, Bryan M, Wei S. What we do when a COVID-19 patient needs an operation: operating room preparation and guidance. Can J Anesth. 2020. Available from: https://doi.org/10.1007/ s12630-020-01617-4.

13. Givi B, Schiff BA, Chinn SB, Clayburgh D, Iyer NG, Jalisi S, et al. Safety Recommendations for Evaluation and Surgery of the Head and Neck During the COVID-19 Pandemic. JAMA Otolaryngol Neck Surg. 2020. doi: 10.1001/jamaoto.2020.0780. [Epub ahead of print]. 